\title{
Communication between coronary sinus and left atrium ${ }^{1}$
}

\author{
Alan G. Rose, ${ }^{2}$ Charles B. Beckman, and Jesse E. Edwards \\ From the Department of Pathology, United Hospitals-Miller Division, St. Paul, Minnesota, and the \\ Departments of Pathology and Surgery, University of Minnesota, Minneapolis, Minnesota, U.S.A.
}

Communication of the coronary sinus with the left atrium is a rare anomaly. In I of 4 cases described it was an incidental finding at necropsy. In each of the remaining 3 the communication provided a vital route for the flow of blood in the presence of an associated obstruction. In one case each, the obstruction took the form of (I) tricuspid atresia with sealed foramen ovale, (2) mitral atresia with sealed foramen ovale, and (3) stenosis of right atrial ostium of coronary sinus.

Gross communication between the coronary sinus and the left atrium is a rare anomaly (Edwards, I960; Mantini et al., 1966). In some instances, this may have functional significance. The present report emanates from the 4 cases of coronary sinus-left atrial communication in the files of the Cardiovascular Registry of United Hospitals-Miller Division (formerly The Charles T. Miller Hospital). In 3 , the communication served as a vital link in providing a route for the flow of blood. The unusual nature of the condition and its functional importance in certain instances stimulates us to describe these cases.

\section{Case reports}

\section{Case I}

The patient was a 43-year-old woman who died of portal cirrhosis. No heart disease had been evident during life. Pathological examination of the heart showed no abnormality apart from the presence of a communication, $1.5 \mathrm{~cm}$ in diameter, between the coronary sinus and the left atrium. The oval opening lay about $2 \mathrm{~cm}$ above the base of the posterior mitral leaflet (Fig. I-3). The coronary sinus terminated in the right atrium in a normal manner and without obstruction. No atrial septal defect was present and the foramen ovale was sealed.

Received 12 July 1973.

1 This study was supported by a U.S. Public Health Service Research grant and a Research Training grant from the National Heart and Lung Institute.

2 On study leave from Department of Pathology, Groote Schuur Hospital, Cape Town, South Africa.
No left superior vena cava was present. The communication between the coronary sinus and the left atrium was an isolated defect which appeared to have no functional significance. Histological examination was made of sections through the posterior wall of the left atrium and the coronary sinus at two locations as follows: one through the intact coronary sinus and one through its communication with the left atrium. The latter showed common absence of the posterior wall of the left atrium and the anterior wall of the coronary sinus (Fig. 2).

\section{Case 2}

The patient was a $2 \frac{1}{2}$-month-old female infant with situs solitus and inversion of the ventricles. The noninverted but transposed great vessels arose from the left-sided, hypoplastic right ventricle. Additional features were a ventricular septal defect, a supravalvular ring above the left atrioventricular valve, persistent ductus arteriosus, and tubular hypoplasia of the aorta. The coronary sinus opened into the right atrium through a grill-like arrangement of tissue which produced some stenosis of the ostium. At the posterior wall of the left atrium there was a conspicuous ostium which communicated freely with the coronary sinus.

In view of the coronary sinus ostial stenosis, it is possible that some of the blood from the coronary sinus drained into the left atrium through the communication with this chamber (Fig. 4).

\section{Case 3}

The specimen from an 18 -month-old male infant showed tricuspid atresia and single ventricle with transposition 

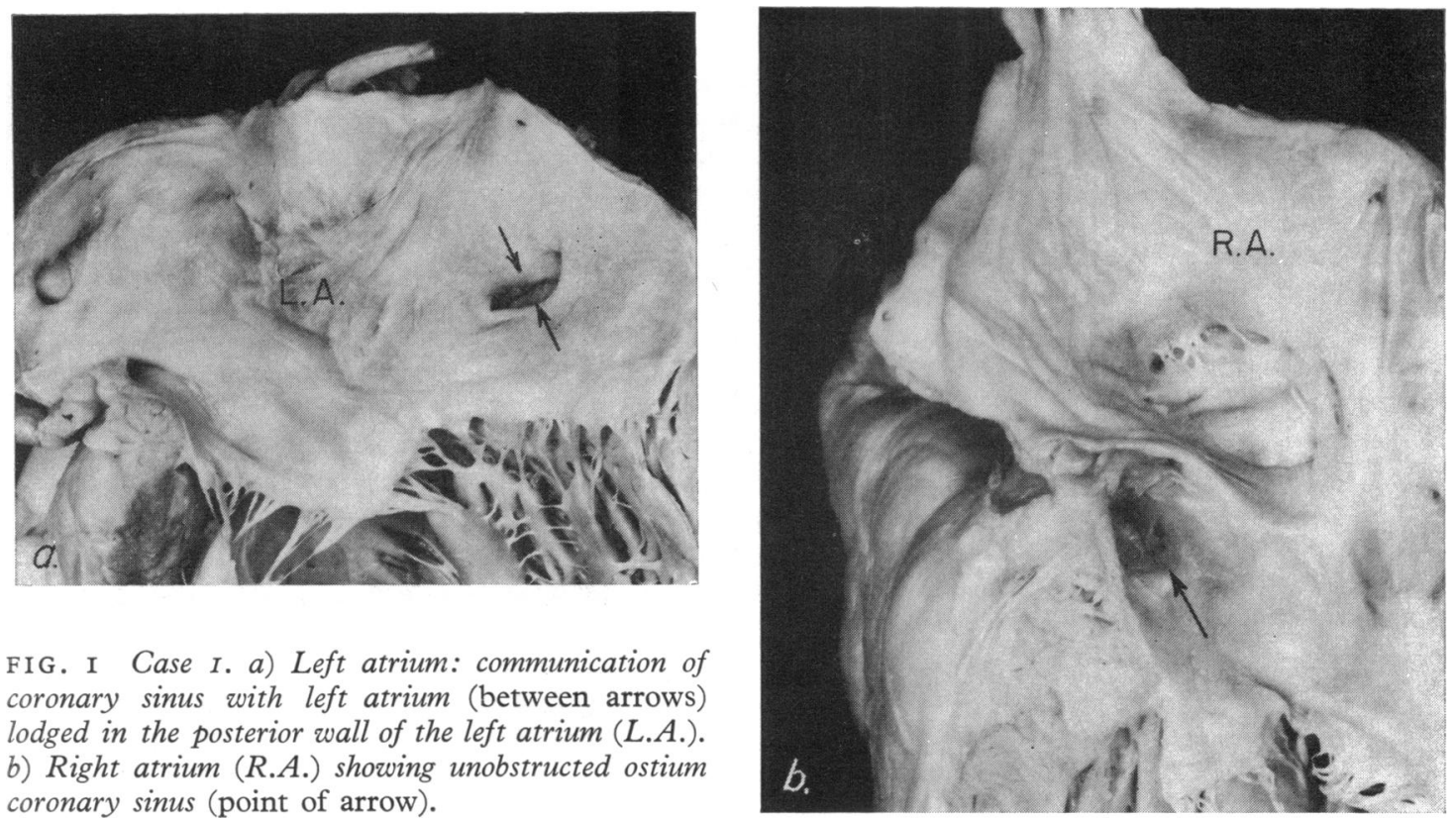

FIG. I Case I. a) Left atrium: communication of coronary sinus with left atrium (between arrows) lodged in the posterior wall of the left atrium (L.A.). b) Right atrium (R.A.) showing unobstructed ostium coronary sinus (point of arrow).

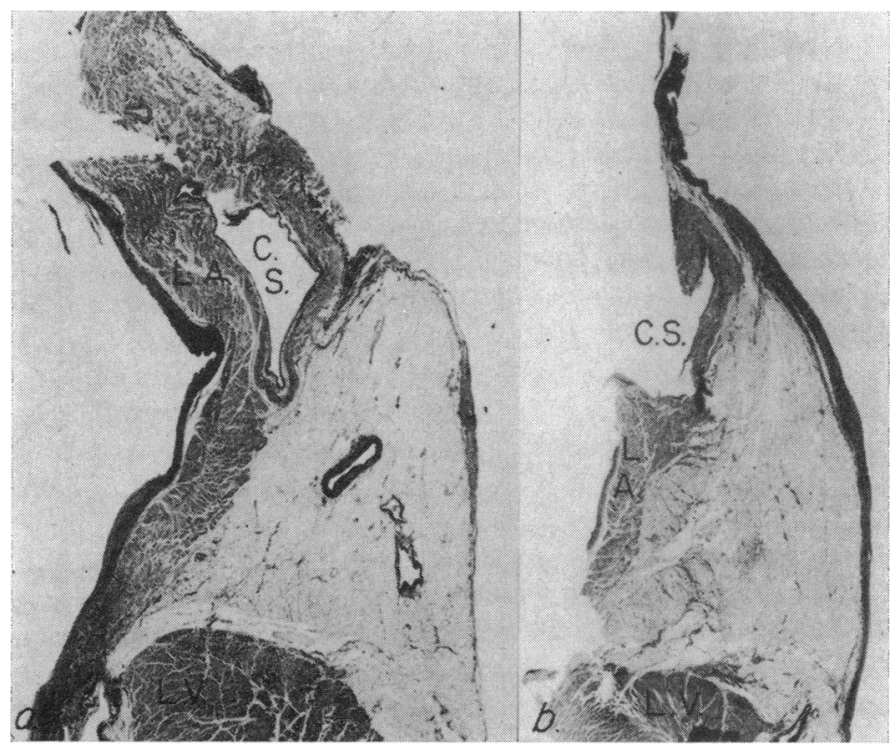

FIG. 2 Photomicrographs through the posterior wall of the left atrium and the coronary sinus. Each elastic tissue stain; $\times 3$. a) At the level of the intact walls. The coronary sinus (C.S.) is separated from the posterior wall of the left atrium (L.A.).b) Section through the communication of the coronary sinus with the left atrium shows absence of the left atrial wall and the anterior wall of the coronary sinus allowing for the communication. 


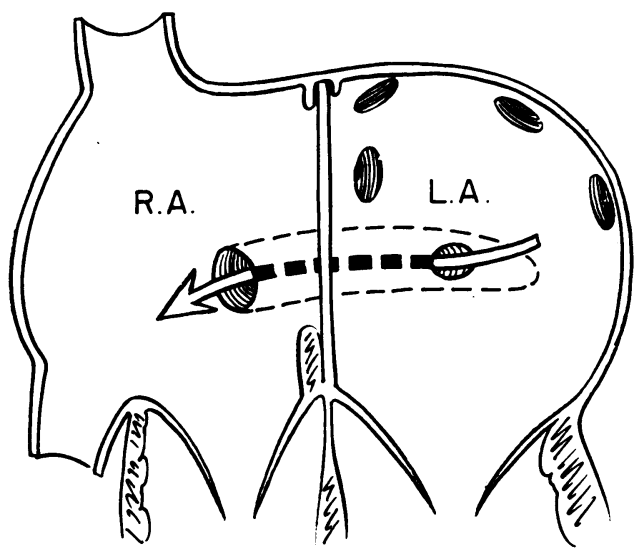

FI G. 3 Diagrammatic portrayal of anatomical features indicated in Fig. $I$.

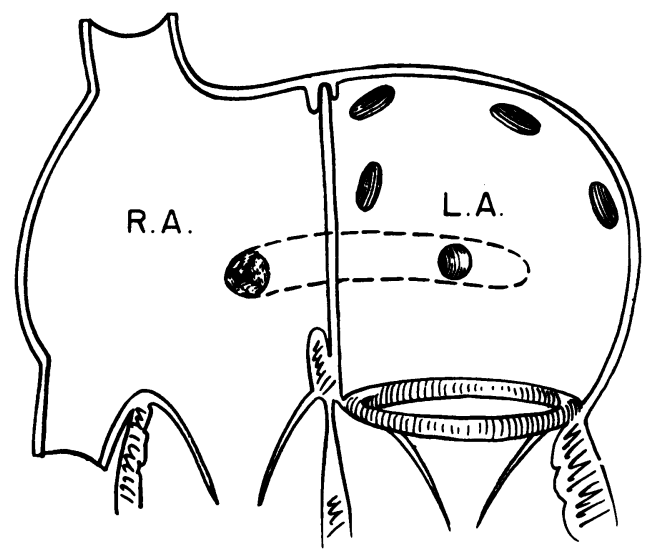

FIG. 4 Case 2. Stenosis of right atrial ostium of coronary sinus associated with communication of coronary sinus with left atrium. The communication allows flow of coronary sinus blood into the left atrium.

of the great vessels. The foramen ovale was sealed. Communication between the left atrium and the coronary sinus consisted of three, closely grouped openings, the largest $\mathrm{I} \mathrm{cm}$ in diameter (Fig. 5). In the presence of tricuspid atresia and an intact atrial septum, the biatrial coronary sinus communication provided the only means of escape of blood from the right atrium into the left (Fig. 6).

\section{Case 4}

The specimen from a I-month-old infant showed mitral valve atresia, stenosis of the right atrial ostium of the coronary sinus, and a left superior vena cava which joined the coronary sinus. The foramen ovale was sealed. Two free communications were present between the left atrium and the coronary sinus. The only means

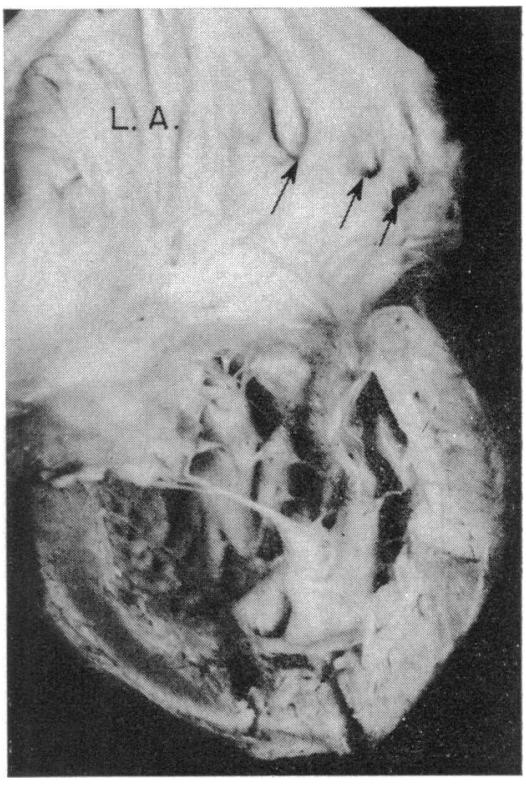

FIG. 5 Left atrium (L.A.) and common ventricular chamber in Case 3 which was an example of tricuspid atresia. Three ostia (arrows) in the posterior wall of the left atrium represent communications of the latter chamber with the coronary sinus.

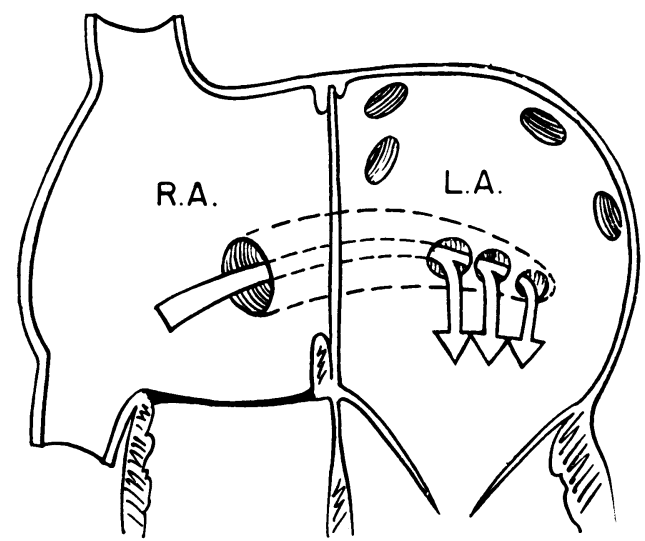

FIG. 6 Case 3. Diagrammatic portrayal of the essential features. In view of the tricuspid atresia and sealed foramen ovale, the coronary sinus with its left ventricular communication allowed the flow of blood from the right atrium into the left atrium.

of escape of blood from the left atrium was through these two openings into the coronary sinus. In view of the stenosis of the right atrial ostium of the coronary sinus, left atrial blood was carried retrogradely in the left superior vena cava and ultimately into the right atrium. 


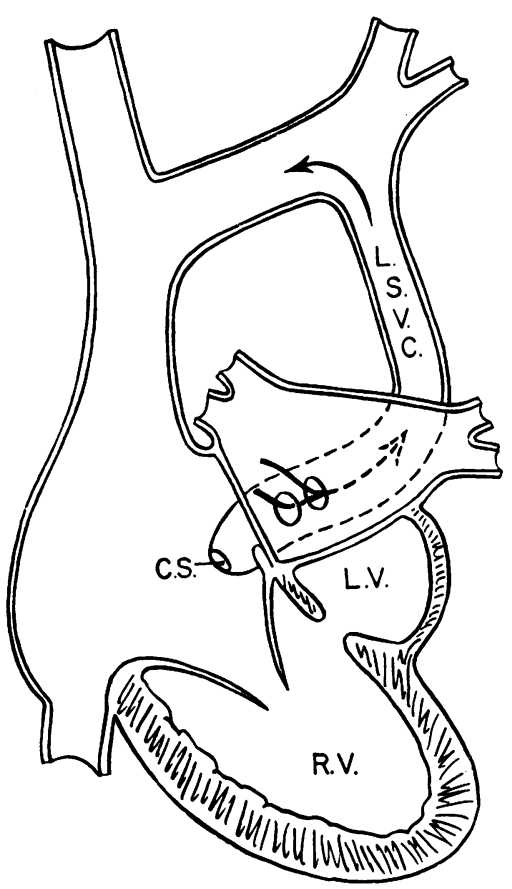

FIG. 7 Case 4. Diagrammatic portrayal of essential findings which were mitral atresia, persistent left superior vena cava joining coronary sinus, and two communications between the coronary sinus and the left atrium. In view of the obstructed right atrial ostium of the coronary sinus (C.S.), blood from the left atrium was carried in retrograde fashion into the left superior vena cava (L.S.V.C.) and ultimately into the right atrium. Small left ventricle (L.V.) communicates with right ventricle (R.V.) through a ventricular septal defect.
Angiocardiograms, which will appear in a detailed description of this case by others, showed the course of blood from the left atrium as indicated in Fig. 7.

\section{Comment}

Raghib et al. (I965) described a developmental complex characterized by (I) union of the left superior vena cava with the left atrium, (2) absence of the coronary sinus, and (3) an atrial septal defect in the anticipated location of the coronary sinus ostium. This complex was explained developmentally on the basis of deficiency of the left atriovenous fold in the developing heart. In our cases a coronary sinus was present but communicated with the left atrium. It is possible that this represents a forme fruste of the condition described by Raghib et al.

The four cases described serve to identify the condition of communication of the left atrium with the coronary sinus as well as identifying ways in which this condition may be compensatory to various obstructive anomalies, either of the atrioventricular valves or the coronary sinus itself.

\section{References}

Edwards, J. E. (1960). Anomalies of the coronary sinus. In Pathology of the Heart, 2nd ed., p. 43I. Ed. by S. E. Gould. Charles C. Thomas, Springfield, Illinois.

Mantini, E., Grondin, C. M., Lillehei, C. W., and Edwards, J. E. (1966). Congenital anomalies involving the coronary sinus. Circulation, 33, 317.

Raghib, G., Ruttenberg, H. D., Anderson, R. C., Amplatz, K., Adams, P., Jr., and Edwards, J. E. (I965). Termination of left superior vena cava in left atrium, atrial septal defect, and absence of coronary sinus. A developmental complex. Circulation, 31, 906.

Requests for reprints to Dr. J. E. Edwards, Department of Pathology, United Hospitals-Miller Division, I25 West College, St. Paul, Minnesota 55I02, U.S.A. 